\title{
Inconsistent Mammography Perceptions and Practice among Women of Over 40 Years in Iran
}

\author{
Fatemeh Pourhaji, Fazlollah Ghofranipour*
}

\begin{abstract}
Objective: This paper aims to report the relationship between perceptions of mammography and screening practices. Methods: This cross-sectional study was conducted between May and September 2017, involving 400 women of over 40 years old, who was referred to as urban health centers in Tehran, Iran. The subjects were selected by multi-stage cluster sampling. Women with inconsistent mammography perceptions and practices were identified the Pros and Cons of mammography behavior for perceptions and Transtheoretical model (TTM) stage of adoption for prior and intended screening practices. The research instrument included a self-administered questionnaire and data were analyzed using descriptive statistics and measures of central tendency, and the chi-square, T-tests, and correlation regression analysis. Results: The average age participant was 45.6 \pm 5.4 . Consistent with the TTM and pros and cons of mammography, women in action tended to have more positive perceptions of mammography than women in pre-contemplation or contemplation (mean decisional balance: action=16.8; SD, 1.4; contemplation=1.8; $\mathrm{SD}, 0.48$; precontemplation= $\mathrm{SD}$, $1.4 ; 0.56 ; \mathrm{p}<0.001)$. Conclusion: results of the current study indicate there are inconsistent mammography perceptions and practice among women in Iran, then we recommend that future intervention, consider setting factors in addition to standard perceptions focused counseling.
\end{abstract}

Keywords: Mammography- screening- transtheoretical model

Asian Pac J Cancer Prev, 20 (5), 1481-1485

\section{Introduction}

Breast cancer is the most common cancer among women worldwide (Tahmasebi and Noroozi, 2016). Breast cancer has been considered as a major health problem among females because of its high incidence in recent years (Mohamed et al., 2016). The prevalence of breast cancer is increasing in Iran (Jarvandi et al., 2002) so that breast cancer is second most common cancer in Iranian women and 14.2 percent of deaths from cancer respectively breast cancer (Guidelines, 2014) and the research was reported the most common age for breast cancer is 40-49 years. Despite the availability of mammograms for early detection of the breast cancer, unfortunately, women's mammography rates are low in developing countries and based on the literature 19-25 percent of deaths from breast cancer to be due to lack of mammography behavior (Mirzaei-Alavijeh et al., 2018). The cancer diagnosis and treatment can be advanced by early detection and it significantly reduces mortality and morbidity, and improve quality of life in women. Mammography is as a standard screening method in early detection and for the highest level of screening and it is said that screening is necessary to achieve a higher level (Alavijeh et al., 2015; Paul et al., 2015). Still, many women are not being screened appropriately, with only $36.5 \%$ of women ages 40 years reporting a screening mammogram in the past 2 years.

Then, interventions to improve screening rates are necessary. Among the most traditional theoretical frameworks for mammography interventions is the Transtheoretical model (TTM) (Sohl and Moyer, 2007; Smith et al., 2010). TTM is a comprehensive model that has been developed in 1970's for assessing the health promotion behaviors (Vahedian Shahroodi et al., 2015). One of the important structures of this model is stage of change, that is focused on understanding and predicting health intent and behaviors. This structure focuses on cognitive factors affecting decisions that a person protects against unhealthy behaviors. TTM states that everyone is not at the same level of readiness (Saffari et al., 2012) and expected the early stage of behavior such as Precontemplation (not ready to adopt) and contemplation (ready to adopt), action phase (beginning to adopt) and maintenance (continous adoption). Furthermore, it recognizes progress process is not necessarily linear and can be relapses. TTM also includes decisional balance that due to motivational and cognitive factors that act as facilitators (pros) and barriers (cons) (Salinas-Martínez et al., 2018). According to Transtheoretical model (TTM), 
any changed behavior occurs step by step and needs appropriate educational interventions proportional to individual's prepared and supporting them to go through different phases of change (Vahedian Shahroodi et al., 2015).

According to increasing breast cancer in Iran, and women's late visit physician, it seems planning health program is essential for cancer early detection (Alavijeh et al., 2015) and the result of the research was shown the perceptions of mammography is an important factor in women's referral for mammography (Parsa and Kandiah, 2010; Madadi et al., 2014).

Structure the observation that perceptions of mammography, as measured by the pros and cons of mammography, tend to be more positive among those who are screening behavior, TTM-based interventions advice women to increase positive perceptions (pros) and decrease negative perceptions (cons), so that they will be more likely to advance through the stage of adoption, moving from pre-contemplation and contemplation (not considering mammography or considering but not yet screening) to action and maintenance (screening and planning to continue) (Clark et al., 1998; Sohl and Moyer, 2007; Vahedian Shahroodi et al., 2015).

The result of the research was shown the perceptions of mammography vary even within the same stage of adoption (Clark et al., 1998). Considering the problems experienced by women about mammography and perceptions as effectiveness factors in screening behavior is necessary. Although this suggests that interventions guided by TTM model may be prepared, more information is needed to describe interactions of factors. Seeking to optimize the effectiveness of theory-based training interventions in women, This study aimed to determine the relationship between perceptions of mammography and screening practices.

\section{Materials and Methods}

A cross-sectional study was conducted on 400 women over 40 years who had been referred to the health centers of Tehran, Iran, in May and September 2017.

The sample size was calculated of the pilot study and by considering $20 \%$ probable rejection rate was estimated 400. A multi-stage cluster sampling was applied. First, from among the 10 health networks at Shahid Beheshti University of Medical Sciences of Iran (SBUMS), were selected the North, East and Shemiranat networks. Then from each health network $(n=3)$, five urban health centers were randomly selected. Then from each health center $(n=15), 27$ women over 40 years were randomly selected. Therefore, the sample size was estimated at $27 \times 15 \approx 400$.

Women who met the following were eligible due to inclusion/exclusion. Inclusion criteria, including over 40 years of age, because the basic mammography is recommended at age 40 . The participants should not have a history of breast cancer in her family and herself. Additionally, the following exclusion criteria were considered: insufficient knowledge of the Persian language, insufficient physical and mental health to fill in the questionnaire.

\section{Measurement}

The research instrument included a self-administered questionnaire with 16 items adapted from the stage of change, behavior positive perceptions (pros) and negative perceptions (cons) relative to mammography, mammography behavior, and demographic variables consist of age, marital status, and educational background.

The stage of change scale was assessed with one question that was applied adapted form (Ajzen, 1991) and (Smith et al., 2010) was testing this statement 'at the moment, Which statement would you choose for mammography?'. There were five answers highlighted: (1) 'I never had a mammogram in the last one year and I also don't intend to do a mammogram in the next year' pre-contemplation; (2) 'I never had a mammogram in the last year and I intend to do a mammogram in the next year'(contemplation); (3) 'I have done mammography at least once in the past year, but I do not intend to do a mammogram in the next year'(risk of relapse); (4) 'I have done mammography once in the past years, I intend to do a mammogram in the next year'(5) (action); 'I have done mammography at least twice in the past two years, I intend to do mammogram in the next year' (maintenance). Perceptions were assessed using the pros and cons of mammography, a validated tool measuring seven positive perceptions (pros) and five negative perceptions (cons) of screening mammography. All items were rated on a five-point Likert scale, where $1=$ strongly disagree and $5=$ strongly agree (Smith et al., 2010).

Inconsistent mammography perceptions and practices were defined by the pros and cons of mammography and TTM stage of adoption. Women had inconsistent perceptions and practices if they either (1) had negative perceptions (cons $\geq$ pros) and were in action and (1) had positive perceptions (pros> cons)(Smith et al., 2010).

The content and face validity of the instrument were verified by a panel of experts and were used for content validity, the Content Validity Ratio (CVR) and the Content Validity Index (CVI). The necessity of an item was assessed through CVR and the items with a score $<0.418$ were deleted according to Lawsh's (Wilson et al., 2012). The final version of the questioner was average content validity $(\mathrm{CVR}=0.80$ and $\mathrm{CVI}-0.79)$ that indicating adequate content validity.

The internal reliability was high for pros (Cronbach coefficient alpha $[\alpha]=0.83)$ and cons $(\alpha=0.87)$. In this study, the mammography behavior intention was the dependent variable.

The reliability was determined by measuring Cronbach's alpha coefficient. To figure out the test stability on stages of change model a consistent coefficient was used with an amount of $90 \%$. A SOC model was assessed with one question.

\section{Statistical Analysis}

Data were analyzed using descriptive statistics and measures of central tendency, and the chi-square tests. All analyses were performed using SPSS (version 20 for Windows; SPSS, Chicago, IL, USA) and a P value of $<0.05$ was considered significant. 


\section{Ethical Considerations}

All participants were informed about the aim of the study, were assured about the confidentiality of study data, and signed the written informed consent prior to enrollment. This study was derived from a doctoral dissertation of the first author in health education and promotion at Faculty of Medical Sciences, Tarbiat Modares University (Ir. TMU. rec. 1395.328). The study was registered in the Iranian registry for clinical trials (registration code: IRCT2017061134472N1).

\section{Results}

Sociodemographic characteristics of women

The mean age of participants was 45.6 (SD, 5.5) and most age groups were 40-44 years (Table 1 ). Nearly $80 \%$ of the women had not a screening mammogram within the previous 2 years. $40 \%$ in pre-contemplation $(n=160)$, $42.5 \%$ contemplation $(n=170)$, or $3.25 \%$ risk of relapse $(n=13), 13 \%$ action $(n=52)$, or $1.25 \%$ maintenance $(n=5)$ (Table 1).

Frequency distribution and percentage of participants based on the SOC model are given in Table 2.

The results were shown 82.5 percent of women were in precontemplation and contemplation, and they had not intention for mammography.

Consistent with the TTM and pros and cons of mammography, women in action tended to have more positive perceptions of mammography than women in precontemplation or contemplation (mean decisional balance: action $=16.8 ; \mathrm{SD}, 1.4$; contemplation $=1.8$; $\mathrm{SD}, 0.48$; precontemplation $=\mathrm{SD}, 1.4 ; 0.56 ; \mathrm{p}<0.001)$. Among women with negative perceptions, 89\% were precontemplation and contemplation, and among those with positive perceptions, $25 \%$ were in action (Table 3 ).

\section{Discussion}

This study aimed to investigate inconsistent mammography perceptions and practice among women in Iran. The recent physician's recommendation, aged $\geq 40$, and interest in routine medical checkups were associated with mammography. Other facilitators and barriers differed according to perceptions, indicating the value of considering additional when designing interventions. In this study draw attention to the consistency of these associations in two groups of women with different perceptions of mammography. The findings suggested that physician's recommendation had the strength to overcome or inactive women's perceptions of mammography. This finding has consisted with (Smith et al., 2010).

In the current study, women with contemplation
Table 1. Characteristics of the Study Population (n-400)

\begin{tabular}{lcc}
\hline Characteristics & $\mathrm{N}$ & $\%$ \\
\hline Age at time of study & & \\
40-44 years & 214 & 53.5 \\
45-49 years & 103 & 25.8 \\
50-54 years & 52 & 13 \\
55-59 years & 11 & 2.7 \\
60 and above & 20 & 5 \\
Educational level & & \\
Elementary & 149 & 37.25 \\
$\quad$ More than elementary & 251 & 62.75 \\
Marital Status & & \\
Single & 13 & 3.25 \\
$\quad$ Married & 352 & 58 \\
Separated & 26 & 6.5 \\
$\quad$ Divorced & 9 & 2.2 \\
\hline
\end{tabular}

Table 2. Frequency Distribution of Participants Based on (SOC)

\begin{tabular}{lcc}
\hline Stage of adoption & $\mathrm{N}$ & $\%$ \\
\hline Precontemplation & 160 & 40 \\
Contemplation & 170 & 42.5 \\
Risk of relapse & 13 & 3.25 \\
Action & 52 & 13 \\
Maintenance & 5 & 1.25 \\
\hline
\end{tabular}

(42.5\%), precontemplation reported higher perceived mammography barriers $(p<0.001)$. In this study, $1.25 \%$ of women were in maintenance phase, while in Maxwell's study was reported 53\% (Maxwell et al., 2006).

It seems that one of the reasons for this is the cultural differences in this study with the present study. However, in developed countries because of health services about breast cancer screening, especially mammography as well as providing perfect training and various through different channels of communication, people may follow and acceptance mammograms. Also the issue may be affect on women's perceptions.

One of the issues that may affect women's performance and perception is the existence of such factors as creating facilities such as mammography centers, increasing knowledge and attitude towards mammography, and appropriate coverage for eligible women (Shirzadi et al., 2017).

In the current study, 82.5 percent of women were in the precontemplation and contemplation. It seems lack of access to the enabling factor that plays a role as a barrier.

Table 3. Subgroups of Women with Inconsistent Mammography Perceptions and Practices

\begin{tabular}{lcccccccc}
\hline TTM stage of adoption & \multicolumn{3}{c}{ Negative/ perceptions (369) } & \multicolumn{4}{c}{ Positive / perceptions (44) } \\
& $\mathrm{n}$ & $\%$ & Mean & $\mathrm{SD}$ & $\mathrm{n}$ & $\%$ & Mean & SD \\
\hline Precon+Contemp & 330 & 89 & -16.8 & 7.11 & 18 & 40.9 & 9.2 & 2.3 \\
Action & 13 & 11 & -14.6 & 6.7 & 13 & 25 & 9.4 & 1.12 \\
\hline
\end{tabular}

Shading denotes subgroups with inconsistent perceptions and practices; TTM transtheoretical model, Precon+Contemp Precontemplation and Contemplation 
Therefore, it is important to improve the mammography level.

This research suggested perceived barrier and perceived benefits of the behavior were significantly associated with mammography adoption among participants. Similar to our finding, several other studies have found perceived barrier and perceived benefits are as the strongest predictors of mammography among different women population (Glanz et al., 2008; Tanner-Smith and Brown, 2010).

In the current study, I do not do mammograms because of my fear of breast cancer, mammography costs is a lot, and not knowing about how to get mammography test were three main cons for mammography among women. Similar to our findings, results of Shirzadi's study this finding is confirmed (Shirzadi et al., 2017). Previous studies have reported a various range of cons to seeking for mammography screening tests including the lack of knowledge (Jones et al., 2014), Fear (Fayanju et al.; AbuHelalah et al., 2015), costs of the test (Watson-Johnson et al., 2011; Abu-Helalah et al., 2015), time-consuming mammography test (Sarma, 2015).

It can be noted that one way to overcome these barriers to improving the health literacy of women and cost-cutting measures by health care sector (Shirzadi et al., 2017).

The study has some limitation that should be noted. First, the data were cross-sectional; thus, the results indicate an association, rather than causation. Also, we did not ask about important factors, such as overall breast health or family history of breast cancer that they may increase the likelihood of getting a mammogram. In addition, there is an ongoing discussion about what age is best for women to take mammograms. Questions regarding social support factor that may influence mammography, such as income status and enabling factors were not included in the study. Another limitation is, even though participants were randomly selected, they all health centers, caution should be used if the results of this study are to be generalized to other parts of Iran.

The finding of this study suggested the lack of systematic screening tests for breast cancer in Iran and uptaking of this preventive service is very low, which is needed for providing such services for early detection of breast cancer. We found (pros) (cons) perceptions component of stage of change as helpful and predictable factors for mammography among Iranian. Then, to consider these factors as enabling factors and designing educational programs can be important for early detection among women. Also, this study has shown there is inconsistent mammography perceptions and practice among women in Iran, then we recommend a future intervention, consider the set factors in addition to standard perceptions focused counseling.

\section{Competing interests}

The authors declare that they have no competing interests.

\section{Authors' Contributions}

FP searched the database and design, collected data and drafted the manuscript. FP, FGH contributed to conception and design of the study and revised the manuscript for intellectual content. FP, FGH designed the study, interpreted data, and revised the manuscript for important intellectual content. All authors read and approved the final manuscript.

\section{Founding Statement}

This research received grant from funding Tarbiat Modares University.

\section{Acknowledgements}

The authors express gratitude to all women who cooperated with this study. We wish to thank the authorities of Tarbiat Modares University, School of health education and promotion.

\section{References}

Abu-Helalah MA, Alshraideh HA, Al-Serhan A-AA, et al (2015). Knowledge, barriers and attitudes towards breast cancer mammography screening in Jordan. Asian Pac J Cancer Prev, 16, 3981-90.

Ajzen I (1991). The theory of planned behavior. Organ Behav Hum Decis Process, 50, 179-211.

Alavijeh MM, Mahboubi M, Jalilian F, et al (2015). Factors related to self-breast examination based on health belief model among Iranian women. Res J Med Sci, 9, 105-8.

Clark MA, Rakowski W, Ehrich B, et al (1998). Stages of adopting regular screening mammography: do women differ in decisional balance within stages?. J Health Psychol, 3, 491-506.

Fayanju OM, Kraenzle S, Drake BF, et al (2014). Perceived barriers to mammography among underserved women in a Breast Health Center Outreach Program. Ame J Surg, 208, 425-34.

Glanz K, Rimer BK, Viswanath K (2008). Health behavior and health education: theory, research, and practice, John Wiley and Sons, pp 1-590.

Guidelines WHO (2014). World Health Organization - Cancer Country Profiles [Online]. [Accessed http://www.who.int/ cancer/country-profiles/irn_en.pdf?ua $=1$.

Jarvandi S, Montazeri A, Harirchi I, et al (2002). Beliefs and behaviours of Iranian teachers toward early detection of breast cancer and breast self-examination. Public Health, 116, 245-9.

Jones CE, Maben J, Jack RH, et al (2014). A systematic review of barriers to early presentation and diagnosis with breast cancer among black women. BMJ Open, 4, e004076.

Madadi M, Zhang S, Yeary KHK, et al (2014). Analyzing factors associated with women's attitudes and behaviors toward screening mammography using design-based logistic regression. Breast Cancer Res Treat, 144, 193-204.

Maxwell CJ, Onysko J, Bancej CM, et al (2006). The distribution and predictive validity of the stages of change for mammography adoption among Canadian women. Prev Med, 43, 171-7.

Mohamed HAE-A, Ibrahim YM, Lamadah SM, et al (2016). Application of the health belief model for breast cancer screening and implementation of breast self-examination educational program for female students of selected medical and non-medical faculties at Umm al Qura University. Life Sci J, 13, 21-33.

Parsa P, Kandiah M (2010). Predictors of adherence to clinical breast examination and mammography screening among 
Malaysian women. Asian Pac J Cancer Prev, 11, 681-8.

Paul S, Solanki PP, Shahi UP, et al (2015). Epidemiological study on breast cancer associated risk factors and screening practices among women in the holy city of Varanasi, Uttar Pradesh, India. Asian Pac J Cancer Prev, 16, 8163-171.

Saffari M, Shojaezadeh D, Ghofranipour F, et al (2009). Health education and promotion Tehran, Sobhan, pp 1-224.

Salinas-Martínez AM, Castañeda-Vásquez DE, García-Morales NG, et al (2018). Stages of change for mammography among Mexican women and a decisional balance comparison across countries. J Cancer Edu, 33, 1230-8.

Sarma EA (2015). Barriers to screening mammography. Health Psychol Rev, 9, 42-62.

Shirzadi S, Nadrian H, Asghari Jafarabadi M, et al (2017). Determinants of mammography adoption among iranian women: What are the differences in the cognitive factors by the stages of test adoption?. Health Care Women Int, 38, 956-70.

Smith SM, Ford JS, Rakowski W, et al (2010). Inconsistent mammography perceptions and practices among women at risk of breast cancer following a pediatric malignancy: a report from the childhood cancer survivor study. Cancer Causes Control, 21, 1585-95.

Sohl SJ, Moyer A (2007). Tailored interventions to promote mammography screening: a meta-analytic review. Prev Med, 45, 252-61.

Tahmasebi R, Noroozi A (2016). Is health locus of control a modifying factor in the health belief model for prediction of breast self-examination?. Asian Pac J Cancer Prev, 17, 2229-33.

Tanner-Smith EE, Brown TN (2010). Evaluating the health belief model: A critical review of studies predicting mammographic and pap screening. Soc Theory Health, 8, 95-125.

Vahedian Shahroodi M, Pourhaje F, Esmaily H, et al (2015). The relationship between breast self-examination and stages of change model in health volunteers. $J$ Res Health, 5, 13-20.

Watson-Johnson L, Degroff A, Steele C, et al (2011). Mammography adherence: A qualitative study. $J$ Womens Health, 20, 1887-94.

Wilson FR, Pan W, Schumsky DA (2012). Recalculation of the critical values for Lawshe's content validity ratio. Measurement and Evaluation in Counseling and Development, 45, 197-210.

This work is licensed under a Creative Commons AttributionNon Commercial 4.0 International License. 